RELACult - Revista Latino-Americana de Estudos em Cultura e Sociedade

\title{
Percorrendo as Veredas das Práticas Translinguajeiras em Contexto Transfronteiriço: Possíveis Travessias no Ensino- Aprendizagem de Língua Portuguesa Adicional
}

\author{
Recorriendo los Caminos de las Prácticas Translenguajeras en \\ Contexto Transfronterizo: Posibles Travesías en la Enseñanza- \\ Aprendizaje de Lengua Portuguesa Adicional
}

\section{Going Through the Paths of Translingual Practices in Transborder Context: Possible Crossings in the Teaching-Learning Process of Portuguese as an Additional Language}

\author{
Henrique Rodrigues Leroy ${ }^{1}$ \\ Maria Elena Pires Santos ${ }^{2}$
}

\begin{abstract}
Resumo
O presente artigo tem o objetivo de discutir sobre como as práticas translíngues (GARCÍA, 2014), transculturais (ORTÍZ, 2002) e descoloniais (MIGNOLO, 2000) são manifestadas na sala de aula de Língua Portuguesa Adicional (PLA) da Universidade Federal da Integração Latino-Americana (UNILA), sediada na cidade de Foz do Iguaçu, Paraná, Brasil, na região da Tríplice Fronteira com a Argentina e o Paraguai. Tais manifestações translinguajeiras, transculturais e descoloniais em sala de aula de PLA em contexto de fronteira são advindas dos textos escritos produzidos pelos estudantes para seus trabalhos finais da disciplina de PLA. Espera-se, assim, que as atividades aplicadas no contexto de sala de aula de PLA possam recombinar, ressignificar e visibilizar as vozes performadas pelos trans-sujeitos aprendizes, abrindo possibilidades para que transitem por uma multiplicidade de lugares e colaborando ativamente nas diversas redes configuradas pelos territórios transfronteiriços.
\end{abstract}

Palavras-Chave: Língua Portuguesa Adicional; Contexto Transfronteiriço; Transculturalidades; Translinguagens; UNILA.

Resumen

\footnotetext{
${ }^{1}$ Mestre em Estudos de Linguagens; Universidade Federal da Integração Latino-Americana - UNILA; Foz do Iguaçu, Paraná, Brasil; henrique.leroy@unila.edu.br. Trabalho apresentado no I Seminário Latino-Americano de Estudos em Cultura - SEMLACult, Foz do Iguaçu/PR, Brasil, 2017.

${ }^{2}$ Doutora em Letras; Universidade Estadual do Oeste do Paraná - UNIOESTE; Foz do Iguaçu, Paraná, Brasil; mel.pires@hotmail.com. Trabalho apresentado no I Seminário Latino-Americano de Estudos em Cultura SEMLACult, Foz do Iguaçu/PR, Brasil, 2017.
} 
El presente artículo tiene el objetivo de analizar como las prácticas translenguajeras (GARCÍA, 2014), transculturales (ORTÍZ, 2002) y decoloniales (MIGNOLO, 2000) son expresadas en la aula de Lengua Portuguesa Adicional (PLA) de la Universidad Federal de la Integración Latinoamericana (UNILA), ubicada en la ciudad de Foz de Iguazú, Paraná, Brasil, en la región de la Triple Frontera con Argentina y Paraguay. Estas expresiones translenguajeras, transculturales y decoloniales en la aula de PLA en contexto de frontera vienen de los textos escritos producidos por los alumnos para sus trabajos finales de la disciplina de PLA. Por lo tanto, este trabajo espera que las actividades aplicadas en el contexto de la aula de PLA puedan recombinar, resignificar y visibilizar las voces producidas por los trans-sujetos alumnos, abriendo posibilidades para que ellos transiten por una multiplicidad de lugares y colaborando activamente en las diversas redes configuradas por los territorios transfronterizos.

Palabras clave: Lengua Portuguesa Adicional; Contexto Transfronterizo; Transculturalidades; Translenguajes; UNILA.

\begin{abstract}
The present paper aims at analyzing how translingual (GARCÍA, 2014), transcultural (ORTÍZ, 2002) and decolonial (MIGNOLO, 2000) practices are enacted in the Portuguese as an Additional Language classroom at the Federal University of Latin American Integration (UNILA), placed in the city of Foz do Iguaçu, Paraná, Brazil, in the Triple Border region with Argentina and Paraguay. These translingual, trancultural and decolonial practices in the Portuguese as an Additional Language classroom in a border context come from written texts which were produced by the students. The professor asked them to produce these written texts for their final papers in the Portuguese as an Additional Language discipline. Therefore, this paper aims at recombining, resignifying and making visible, through the activities applied inside the classroom, the voices which are produced by the trans-subjects. It can open the possibilities for them to walk through a multiplicity of places and to actively collaborate in the diversity of nets which are configurated in transborder territories.

Key-words: Portuguese as an Additional Language; Transborder Context; Transculturalities; Translanguaging; UNILA.
\end{abstract}

Imaginem uma sala de aula de Língua Portuguesa Adicional $^{3}$ composta por estudantes advindos de diferentes nacionalidades latino-americanas e caribenhas, mais especificamente chilenos, colombianos, haitianos e salvadorenhos. Imaginem também a condução e a negociação dessas interações linguístico-culturais sendo feitas por um professor de nacionalidade brasileira. Somem-se a essas características o interessante fato de esta sala de aula estar localizada na Tríplice Fronteira mais movimentada do Brasil, mais especificamente na cidade de Foz do Iguaçu, no Estado do Paraná, bem na divisa entre Ciudad Del Este, no Paraguai e Puerto Iguazú, na Argentina, mais pontualmente na Universidade Federal da Integração Latino-Americana (UNILA). Entretanto, nacionalidades diferentes elegem línguas nacionais e oficiais como propostas unificadoras e homogeneizadoras, desconsiderando suas pluralidades linguístico-culturais.

\footnotetext{
${ }^{3}$ Adotamos o termo língua adicional neste trabalho, corroborando a definição de Schlatter e Garcez (2009) para esse termo, para expressar que essa língua nos pertence e não é estrangeira para nós. Por isso, os estudantes escolhem adicioná-la aos seus repertórios linguísticos idiossincráticos com o objetivo de fazerem uso dela em suas práticas sociais.
} 
Tomando agora outras veredas como percurso, imaginem esta mesma sala de aula descrita acima com toda sua diversidade linguístico-cultural vista e analisada por meio das lentes das translinguagens (GARCIA \& WEI, 2014), das transculturalidades (ORTÍZ, 2002) e dos Estudos Culturais descoloniais (MIGNOLO, 2000), indo além do construto da nação colonial/moderna com sua língua dominante e oficial e toda a epistemologia acadêmica colonial/dominadora que ela implica. Esta nova leitura traz à luz uma perspectiva linguísticocultural translíngue e descolonial que pode ser aplicada na sala de aula de Língua Portuguesa Adicional em contexto de fronteira, valorizando os saberes das línguas consideradas subalternas e marginalizadas pelo sistema colonial/moderno (MIGNOLO, 2000) e ressaltando as transculturalidades (ORTÍZ, 2002) e o repertório linguístico vivo, dinâmico e próprio do falante translíngue (GARCIA \& WEI, 2014). Tais repertórios são compostos por duas ou mais línguas, pois esses estudantes, além de línguas indígenas e da língua crioula haitiana ${ }^{4}$, também falam as línguas espanhola, francesa e portuguesa. Tais veredas teóricas que decidimos percorrer neste artigo, quais sejam, os estudos culturais descoloniais e os estudos translíngues, distancia-nos daquela perspectiva colonial/moderna e desconstrói a ideia colonizadora de uma língua, de um povo e de uma nação.

Para as discussões aqui propostas, tomamos como referência o que o escritor, médico e diplomata mineiro e universal João Guimarães Rosa foi para a literatura por meio de obras-primas como "Grande Sertão: veredas" e "Primeiras Estórias" com todas as suas travessias, entre-lugares ${ }^{5}$ e terceiras margens. Utilizamos metáforas roseanas como veredas, travessias e sertões para fazer alusão às terceiras margens, ou entre-lugares, também criadas pelas práticas "translíngues" (CANAGARAJAH, 2011; GARCIA \& LEIVA, 2014), para fazer referência ao repertório linguístico dinâmico e vivo que é próprio do sujeito plurilíngue, como esclareceremos mais adiante.

Assim como os neologismos e inventividades discursivas geniais de Guimarães Rosa foram para a literatura, o conceito transgressor de translinguagem pode ser para a Pedagogia Translíngue (CELIC \& SELTZER, 2012; GARCÍA \& LEIVA, 2014) a qual preconiza a superação dos limites das línguas como códigos e estruturas unificadas - como se

\footnotetext{
4 Falada por quase toda a população haitiana, é muito influenciada pela língua francesa (90\% do seu vocabulário), pelo taino (língua nativa da ilha caribenha) e por algumas línguas do oeste da África, como o iorubá, o fon e o ewé. O crioulo haitiano, juntamente com a língua francesa, é considerado língua oficial do Haiti.

${ }^{5} \mathrm{O}$ conceito de entre-lugar ou in-between é atribuído a Homi Bhabha (2004), quando se refere à criação de um terceiro espaço advindo da interação entre culturas.
} 
as línguas estivessem separadas em caixinhas dentro deste sujeito - e ruma para além das suas próprias fronteiras, ou seja, as práticas translinguageiras preconizam a perspectiva do falante, o qual produz traços linguísticos diversos, por meio de um repertório linguístico dinâmico que lhe é próprio. Destarte, o presente trabalho pretende verificar como as práticas translinguajeiras, transculturais e descoloniais se manifestam na sala de aula de Língua Portuguesa Adicional em contexto transfronteiriço ${ }^{6}$.

Para tanto, formulamos a seguinte pergunta: considerando a sala de aula de Língua Portuguesa Adicional como um entre-lugar e uma terceira margem descolonial e transcultural, bem como considerando a visão dinâmica do falante translíngue, como se manifestam os discursos translinguajeiros, na sala de aula de Português Língua Adicional (PLA)? Assim, o presente trabalho voltará seus olhos para o aluno e o professor como trans-sujeitos (GARCÍA \& LEIVA, 2014), para quem os trans-sujeitos são falantes bilíngues ou plurilíngues que fazem uso das translinguagens, produzindo um novo discurso advindo de um repertório linguístico próprio, vivo e dinâmico. Os trans-sujeitos são então aqueles que deixaram seus sertões e foram para além de suas fronteiras, sejam elas exteriores ou interiores, sejam eles da Colômbia, do Chile, de El Salvador ou do Haiti, cada qual com suas experiências, histórias de vida e repertórios linguísticos próprios e dinâmicos. Com base nesse movimento de atravessar suas fronteiras físicas, culturais e emocionais, consideramos todos esses trans-sujeitos como transculturais, pois eles estão habitando um terceiro espaço configurado por trânsitos culturais fluidos e constantes.

O artigo está organizado nas seguintes seções: primeiramente, fazemos uma apresentação panorâmica do cenário da pesquisa e seus sujeitos; na segunda seção, discorremos sobre as veredas teóricas percorridas visando à fundamentação deste trabalho. Em seguida, na terceira seção, expomos a Pedagogia Translíngue, para enfim, na quarta seção, colocá-la em prática por meio das análises das práticas translinguajeiras, transculturais e descoloniais manifestadas na sala de aula de Língua Portuguesa Adicional, na Tríplice Fronteira mais movimentada do país.

\footnotetext{
${ }^{6}$ Carneiro (2016) discute os construtos de regiões transfronteiriças e transfronteirizações como conceitos em construção. O primeiro seria caracterizado pela porosidade existente nas regiões entre dois ou mais países, onde a abertura prevalece sobre o fechamento, um lugar vivo, dinâmico e complexo que prepara o terreno para os processos de transfronteirizações, quando seus habitantes transcendem as fronteiras, valorizando e incorporando em suas estratégias de vida, hábitos que já não podem mais ser limitados a um país ou outro.
} 


\section{O contexto transfronteiriço e os trans-sujeitos}

O Brasil, país de tamanho continental com mais de 8,5 milhões de $\mathrm{km}^{2}$, possui 10 municípios situados em tríplices fronteiras. Dentre elas, encontramos a Tríplice Fronteira entre o Brasil, a Argentina e o Paraguai considerada a mais movimentada e populosa, em razão de seu caráter turístico e de sua configuração econômica e politicamente estratégica. Do lado argentino, está a cidade de Puerto Iguazú, na Província de Misiones com aproximadamente 80.020 habitantes, do lado paraguaio, localiza-se Ciudad Del Este, na Província de Alto Paraná, a segunda maior cidade do Paraguai e maior cidade desta Tríplice Fronteira, contando com aproximadamente 387.000 pessoas e, do lado brasileiro, a cidade de Foz do Iguaçu, no Estado do Paraná, separada de Puerto Iguazú pelo rio Iguaçu e de Ciudad Del Este pelo rio Paraná.

Foz do Iguaçu possui uma população de 263.915 habitantes, conforme estimativa do Instituto Brasileiro de Geografia e Estatística (IBGE), de agosto de 2016. É conhecida internacionalmente pelas Cataratas do Iguaçu - uma das vencedoras do concurso que escolheu as 7 Maravilhas da Natureza - e pela Usina Hidrelétrica de Itaipu, a segunda maior do mundo em tamanho e primeira em geração de energia, que em $\underline{1996}$ foi considerada uma das $\underline{7}$ Maravilhas do Mundo Moderno pela Sociedade Americana de Engenheiros Civis. É considerada, ainda, um dos municípios mais multiculturais do Brasil, onde estão presentes habitantes de mais de $80^{7}$ nacionalidades, entre estas italianos, alemães, ucranianos, japoneses, árabes, haitianos, sendo as mais representativas a libanesa, a chinesa, a paraguaia e a argentina.

Nesse cenário, foi criada A Universidade Federal da Integração Latino-Americana (UNILA), pela Lei $\mathrm{n}^{\circ}$ 12.189/2010, cuja vocação contempla a pluralidade linguística e cultural da região, ou seja, sua vocação é o intercâmbio acadêmico e a cooperação solidária com países integrantes do Mercosul e com os demais países da América Latina e do Caribe, em áreas consideradas estratégicas para o desenvolvimento e a integração regionais.

De acordo com a seção III do Regimento Geral da universidade, quando discorre sobre o Ciclo Comum de Estudos, este é parte integrante da missão da UNILA e obrigatório a todos os discentes matriculados na graduação, contemplando-se os seguintes conteúdos: (i)

\footnotetext{
${ }^{7}$ Disponível em

http://www.pmfi.pr.gov.br/conteudo/\%3bjsessionid\%3d62b17adaaee52db1094cf08d8af7?idMenu=1004, acesso em 20/04/2017.
} 
Estudo Compreensivo sobre a América Latina e Caribe (Fundamentos da América Latina); (ii) Epistemologia e Metodologia e (iii) Línguas Adicionais Portuguesa e Espanhola. Seguindo estas orientações, os alunos brasileiros cursam Língua Espanhola Adicional e os alunos estrangeiros cursam Língua Portuguesa Adicional. As disciplinas do Ciclo Comum de Estudos são cursadas em três semestres. No caso das Línguas, os estudantes têm que cursar os três primeiros níveis, quais sejam, os níveis básico, intermediário I e intermediário II. O nível avançado é destinado para aqueles que queiram se aprofundar nos estudos linguísticoculturais. Para participar da seleção internacional com o intuito de conquistar uma vaga nos 29 cursos de graduação oferecidos pela UNILA, os alunos não brasileiros devem preencher um formulário eletrônico disponível na página da instituição com suas informações pessoais e anexar diversos documentos exigidos para esse processo, como carteira de identidade, certidão de nascimento, certificado de conclusão de Ensino Médio, histórico de notas e uma ficha de declaração. Além da conclusão do Ensino Médio, esse candidato deverá ser maior de dezoito anos e não portar nenhum tipo de visto do Brasil. Ele também não necessita ter conhecimento em Língua Portuguesa, pois um curso de acolhimento linguístico-cultural é oferecido à distância para esses candidatos. Todo o processo de seleção é gratuito. Almejando a uma formação superior de excelência destinada ao desenvolvimento e integração latinoamericanos, os atuais 3.575 estudantes da UNILA são oriundos de 20 países, abarcando a América do Sul, a América Central, o Caribe e a América do Norte.

É importante ressaltar que este artigo faz parte de um trabalho mais amplo, que é a minha pesquisa de Doutorado. Portanto, apresentarei aqui apenas uma pequena parte do universo de sujeitos e dos registros gerados nesse contexto. A análise aqui proposta recai sobre portfólios escritos pelos alunos das disciplinas de Língua Portuguesa Adicional dos níveis Básico, Intermediário I e Intermediário II, que teve como finalidade se autoavaliarem em relação ao aprendizado da Língua Portuguesa e também avaliarem os materiais utilizados na disciplina, bem como avaliarem o professor e a metodologia empregada em sala de aula.

A seguir, apresentaremos os sujeitos envolvidos neste trabalho específico, abarcando estudantes e o professor.

Licenciado em Língua Inglesa pela Universidade Federal de Minas Gerais (UFMG) e mestre em Estudos de Linguagens com foco no ensino-aprendizagem de Língua Portuguesa Adicional pelo Centro Federal de Educação Tecnológica de Minas Gerais (CEFET-MG), sou professor do quadro efetivo da UNILA de Língua Portuguesa Adicional. Este artigo contempla discentes estrangeiros oriundos dos níveis básico, intermediário I e intermediário II 
de Língua Portuguesa Adicional. As aulas aconteceram no segundo semestre de 2015 e nos dois semestres de 2016.

Os sujeitos desta pesquisa são de diversos países da América Latina e do Caribe, quais sejam, Chile, Colômbia, El Salvador e Haiti, e todos eles cursam as disciplinas de Língua Portuguesa Adicional da UNILA. Foram considerados excertos translíngues dos seguintes alunos: uma aluna colombiana de nível básico, pertencente ao curso de Arquitetura e Urbanismo; um aluno colombiano de nível básico, do curso de Biotecnologia; uma aluna haitiana de nível intermediário II, pertencente ao curso de Ciências Econômicas - Economia, Integração e Desenvolvimento; um aluno salvadorenho, do curso de Engenharia de Energias Renováveis, de nível intermediário II; uma aluna chilena, do nível Intermediário I, pertencente ao curso de Ciências Econômicas: Economia, Integração e Desenvolvimento.

A seguir, percorreremos e atravessaremos as veredas teóricas que fundamentam este trabalho.

\section{Veredas que fundamentam as práticas translíngues}

De acordo com García \& Leiva (2014), o conceito de translinguagem (trawsieithu) foi criado no País de Gales por Cen Williams, em 1994, sendo traduzido para o inglês somente em 2001 por Colin Baker. Para Williams, a ideia era que os alunos lessem um texto em língua inglesa e escrevessem algo sobre o que haviam compreendido do texto, em galês. Assim, nessas práticas pedagógicas, os alunos utilizaram duas línguas ou mais para fins pedagógicos de leitura, escrita, fala e escuta. Desde então, de acordo com García \& Leiva (2014), muitos outros acadêmicos têm estudado o conceito de translinguagem, como, por exemplo, Blackledge \& Creese (2010), Canagarajah (2011), Creese \& Blackledge (2010), García (2009, 2011), García \& Silvan (2011), Hornberger \& Link (2012) e Lewis et al. 2012a, b. García tem usado este termo para se referir às práticas do sujeito bilíngue ${ }^{8}$, quando este faz uso flexível de todo o seu repertório linguístico. Para a autora, translinguagem refere-se às práticas do bilíngue emergente, o qual possui um repertório linguístico com características que são contínuas, que estão sempre sendo construídas, contemplando traços linguísticos de diferentes

\footnotetext{
${ }^{8}$ Para García \& Wei (2014), todas as vezes que se referirem a falantes bilíngues, na verdade, estão se referindo a falantes multilíngues e plurilíngues, pois consideram que o -bi não se refere a duas línguas somente, mas a complexas interações linguísticas que não podem ser elencadas.
} 
línguas e podendo os bilíngues emergentes atravessarem ou deslizarem por entre-lugares, por essas terceiras margens. Segundo García (2009) e García \& Kleigfen (2010), este uso dos repertórios linguísticos dos bilíngues emergentes libera a voz dos alunos que são marginalizados e considerados minoria na sala de aula.

García (2009) teoriza este conceito baseando-se em suas experiências e em sua história como cubana e latino-americana, radicada em Nova York desde os onze anos de idade. Assim, ela envereda por caminhos chilenos, cubanos e argentinos. No Chile, ela transita pela Biologia e dialoga com os biólogos Humberto Maturana e Francisco Varela para tecer ideias sobre o conceito de autopoieis, languaging, lenguajear ou linguajamento ${ }^{9}$. Em Cuba, sua terra natal, ela percorre os caminhos da Antropologia, conversando com o antropólogo Fernando Ortiz, para tergiversar sobre o conceito de transculturação (transculturación) ${ }^{10}$. Já na Argentina, ela se envolve com os Estudos Culturais, para então, na interação com o teórico cultural e descolonial Walter Mignolo, entrelaçar sua teoria translíngue com os conceitos de colonialidade (coloniality) e pensamento liminar ou fronteiriço (border thinking). Justifica-se, aqui, o fato deste artigo trabalhar com esses conceitos criados por pensadores latinoamericanos, uma vez que o contexto desta pesquisa é a Universidade Federal da Integração Latino-Americana (UNILA), localizada na Tríplice Fronteira mais movimentada do Brasil. Ademais, todos os trans-sujeitos emergentes bilíngues deste trabalho são caribenhos e latinoamericanos.

Quando García foca na translinguagem, ela põe os holofotes sobre o conceito do linguajamento, ou seja, ela discorre sobre qual concepção de língua/linguagem é basilar para a translinguagem. De acordo com García e Leiva (2014), as concepções sociais, contextuais e culturais de linguagem foram previstas pelos biólogos chilenos Humberto Maturana e Francisco Varela, os quais, em 1973, cunharam o termo lenguajear ou lenguajeo, em espanhol, ou languaging, em inglês, para se referirem ao fato de que a linguagem é resultado da imbricação fluida e líquida entre ações e práticas biológicas, psicológicas e sociais. Eles desenvolveram a teoria da autopoiesis. "Auto", em grego, significa "próprio"; "poiesis" significa "criação". Portanto, autopoiesis significa "criação própria”. Esse termo, de acordo com Maturana e Varela (1998), designa a capacidade de um ser vivo criar ou produzir a si próprio. Para esta teoria, o sistema autopoiético de qualquer ser vivo produz moléculas que, ao interagirem com outras moléculas ou

\footnotetext{
${ }^{9}$ Todos esses conceitos serão explicados adiante.

${ }^{10}$ Conceito que também será explicado adiante.
} 
processos moleculares, produzem a mesma rede de moléculas que produziu o ser vivo. Por exemplo, o metabolismo celular, por meio de reações moleculares diversas, produz a membrana celular. Essa membrana celular, por meio de reações moleculares e transformações dinâmicas, produz as mesmas reações que a produziram como membrana, desencadeando operações autopoiéticas ou autocriativas. Esses processos mostram que o ser e o fazer de uma unidade autopoiética são inseparáveis. A conservação desse processo de autopoiesis desencadeia a sobrevivência do indivíduo nos meios onde habita, pois estará sempre se reinventando, se recriando, para se adaptar e sobreviver. Argumentando nessa direção, para García e Leiva (2014) o linguajamento é uma prática autopoiética, relacionando-se com a autopoiesis na medida em que não se pode separar a nossa história de ações biológicas e sociais. O que acontece no processo autopoiético também acontece no processo linguajeiro. A linguagem é um processo contínuo que existe somente por meio do linguajamento. O linguajamento é uma forma de viver, uma ação humana contínua interminável e não-terminada, que sempre ocorre em um contexto específico. $\mathrm{Na}$ leitura que fazem de Maturana e Varela, as autoras afirmam que:

Para Maturana e Varela, o linguajamento autopoiético refere-se à simultaneidade do ser e do fazer a linguagem nos produzindo como indivíduos e, ao mesmo tempo, nos constituindo diferentemente na medida em que interagimos com os outros. O entendimento deles sobre o nosso ser constituído na linguagem "em um ser contínuo" se refere aos postulados bakhtinianos, segundo os quais nós estamos sempre nos transformando contextualmente por meio do contato com os outros. A translinguagem é estabelecida por meio do contato com o outro, que é sempre infinito e infindável, possibilitando assim, diversas ações para a justiça social. (GARCÍA \& LEIVA, 2014, p. 202, minha tradução) $)^{11}$

Lembrando o caráter transgressor de Guimarães Rosa, que transformou e ainda continua transformando as realidades das manifestações artísticas culturais, a teoria translíngue não é sobre a mudança de um código linguístico para outro código, mas sim uma visão distinta e transformadora da realidade linguística. Por esta razão, para fundamentar o conceito de translinguagem, Ofelia García dialoga com outros dois teóricos latino-americanos, o

\footnotetext{
11 "For Maturana and Varela, autopoietic laguaging refers to the simultaneous being and doing of language as it brings us forth as individuals, at the same time that it continuously constitutes us differently as we interact with others. Their understanding of our being constituted in language in a continuous becoming is reminiscent of Bakhtin's claim that we are always becoming through contextually bound contact with others. Translanguaging is enacted through contact with others that is always unfinished and unfinishable, thus, enabling the possibilities of acting for social justice." (GARCÍA \& LEIVA, 2014, P. 202)
} 
antropólogo cubano Fernado Ortíz, que vai discorrer sobre transculturação (transculturación) e o teórico cultural argentino Walter Mignolo, que enveredará pelos conceitos de colonialidade (coloniality) e pensamento liminar (border thinking). O linguajamento relacionado a esses trans-conceitos enfatizará e focará uma nova e transformadora prática, produzido por um novo trans-sujeito. O linguajamento, associado aos trans-conceitos, possibilitará a transformação da sala de aula convencional em um entre-lugar novo, fluido e transgressivo. Com a finalidade de justificar a criação de veredas e travessias para um espaço novo e transgressivo na sala de aula de Língua Portuguesa Adicional, daremos continuidade ao embasamento teórico para a sua realização.

O antropólogo cubano Fernando Ortíz, por meio de sua obra "Contrapunteo cubano del tabaco y del azúcar", de $1940^{12}$, introduziu o conceito de transculturação (transculturación), referindo-se ao complexo e multidirecional processo na transformação cultural cubana.

Nesta obra, Ortíz faz uma análise da mudança cultural em Cuba por intermédio de um estudo comparativo de dois produtos cubanos que fizeram e ainda fazem parte da vida das pessoas em todo o planeta: o tabaco e o açúcar. Em língua portuguesa, o título do ensaio desenvolvido por Ortíz é "O Contraponto cubano do tabaco e do açúcar”. Digo isto porque a palavra "contraponto" é fundamental para o entendimento dessa obra. O antropólogo cubano Fernando Ortíz tirou esse termo "contraponto" da música. Na música, o contraponto é a arte de combinar, segundo certas regras, duas ou mais melodias diferentes, podendo se referir também ao contraste entre dois aspectos diferentes. Na música popular cubana, o vocábulo "contraponto" refere-se à "disputa" de ditos populares e rimas entre duas ou mais pessoas, no estilo do nosso conhecido repente nordestino, em que os artistas tocam instrumentos e improvisam as rimas. Assim, Ortíz (2002) elege um termo que faz alusão ao gênero dialógico que leva à arte, a dramática dialética da vida, o que é característico da tradição folclórica cubana. Ortíz (2002) explica que o tabaco e o açúcar são os personagens mais importantes da história de Cuba. Todos os contrastes acabam por se transformarem no que Ortíz chama de transculturação:

\begin{abstract}
"Um processo em que ambas as partes da equação são modificadas. Um processo em que uma nova realidade emerge, composta e complexa; uma realidade que não é uma aglomeração mecânica de características, nem mesmo um mosaico, mas sim um novo fenômeno, original e independente " (ORTÍZ, 2002, p.4).
\end{abstract}

\footnotetext{
${ }^{12}$ Esta obra possui inúmeras traduções. Neste trabalho, utilizamos a tradução para o inglês feita em 2002.
} 
Nesse conceito de transculturação está o âmago do questionamento da pureza epistemológica das línguas autônomas, enunciadas por aqueles que detêm o poder, como os indivíduos de grupos sociais e nacionais. Assim, a transculturação não é simplesmente uma adaptação passiva a um padrão local ou cultural estático. A transculturação dissolve diferenças para criar novas realidades. Não são duas identidades fixas que são combinadas. A transculturação é um espaço que cria uma nova realidade porque nenhuma parte da equação é vista como estática ou dominante, mas sim operando dentro de uma rede dinâmica de transformações culturais. Este novo espaço onde se dará o concerto transgressivo na sala de aula é o entre-lugar ou a terceira margem, que está fundamentado na vereda teórica da transculturação. Coronil (1995) explica que o conceito de transculturação oxigena categorias reificadas, consideradas como objetos concretos, trazendo à tona abertas e concebidas trocas entre as pessoas e libertando histórias que estavam enterradas juntamente às suas identidades fixas.

Para que as manifestações translíngues, transculturais e descoloniais sejam manifestadas no espaço transgressivo da sala de aula na fronteira trinacional mais movimentada do Brasil, criando seus entre-lugares e terceiras margens, ainda falta percorrer as veredas e as travessias teóricas criadas pelo pensador descolonial argentino Walter Mignolo, que afirma que a transculturação envolve o pensamento liminar ou fronteiriço e a colonialidade. Mignolo vê o pensamento liminar como o pensamento concebido fora das fronteiras do sistema mundial moderno/colonial (MIGNOLO, 2000, p. 11) e como o pensamento entre duas línguas e suas relações históricas (MIGNOLO, 2000, p. 74). O pensamento liminar atesta que há conexões entre o lugar de onde se teoriza e os lugares de onde se estabelece politicamente nossos lugares de enunciação. Mignolo vê o estabelecimento político de "uma outra língua" como uma maneira de romper com os projetos globais para desenvolver "um outro pensamento", um entre-lugar, uma terceira margem. Esta "outra língua", que caracteriza a terceira margem, tem o objetivo de descolonizar os saberes intelectuais dominantes, incluindo as linguagens. Mignolo (2000) chama este pensar entre línguas de bilinguajamento. Par ele, bilinguajar é uma forma de viver entre duas ou mais línguas, de existir, de lutar, de se estabelecer politicamente, de sobreviver e de permanecer em um mundo ditado por um sistema colonial/moderno. É uma maneira de inclusão das línguas não dominantes visando à transformação e à libertação sociais e acadêmicas. Ele também afirma que este bilinguajamento só será possível se considerarmos o linguajamento de Maturana e Varela (1998) como prática cultural e como luta pelo poder desde a perspectiva da diferença colonial, isto é, desde a perspectiva descolonial, de valorização dos saberes subalternos e 
descolonização dos saberes dominantes. E, por fim, Mignolo (2000) considera o fato de que a transculturação de Ortíz (2002) seja também considerada pelas lentes simbólicas da representação dos poderes coloniais que estão em cena. $\mathrm{O}$ fato de estarmos utilizando de autores teóricos latino-americanos neste texto para a construção de um espaço transgressivo em sala de aula de Língua Portuguesa Adicional em contexto de fronteira também reflete este entre-lugar de descolonização dos saberes dominantes. Mignolo afirma que essa "outra língua", que ele chama de bilinguajamento, transforma o local de enunciação (MIGNOLO, 2000, p. 220). É a partir dessa posição liminar, fronteiriça e transcultural de práticas sociais e ações "entre" duas línguas que não são mais estáticas ou vinculadas a uma identidade nacional é que, de acordo com García e Leiva (2014), surge o que elas chamam de translinguagem. Para elas, na translinguagem o falante está situado em um espaço onde representações e enunciações alternativas podem ser geradas por meio de histórias que são desenterradas e libertadas para serem ouvidas e onde saberes conflituosos são produzidos. Para Garcia (2014), a translinguagem refere-se às práticas sociais e ações que estabelecem um processo político de transformações sociais e subjetivas, que, por sua vez, relembrando o processo autopoiético do linguajamento, produz translinguagens. Além de desafiar a visão das línguas como autônomas e puras, a translinguagem, como um produto do pensamento liminar, do saber subalterno e marginalizado concebido a partir de um entre-lugar bilíngue, muda o local de enunciação e resiste às assimetrias de poder que os "códigos bilíngues" criam com frequência.

García (2014) afirma que conceitos tradicionais de bilinguismo insistem que os falantes performam dois "códigos" de uma maneira aditiva, de acordo com os "padrões" criados por poderosas agências, como as escolas ou as nações. Portanto, falantes bilíngues cujos linguajamentos não se encaixam nas enunciações do poder são estigmatizados e excluídos. Assim, a translinguagem para ela resiste às posições históricas e culturais do monolingualismo ou do bilinguismo aditivo, libertando os falantes de se conformarem com um “monolingualismo paralelo" (HELLER, 1999 apud GARCÍA \& LEIVA, 2014).

Agora que as veredas teóricas foram descritas, temos a possibilidade de descrever e analisar como nossos entendimentos de translinguagens, transculturação e pensamento liminar ou fronteiriço aparecem e estabelecem politicamente o espaço transgressivo ou o entre-lugar ou a terceira margem de Guimarães Rosa que é a sala de aula de Língua Portuguesa Adicional na fronteira entre Brasil, Argentina e Paraguai, mais especificamente na cidade de Foz do Iguaçu, em uma instituição transgressiva, que valoriza as descolonizações 
dos saberes intelectuais dominantes, chamada Universidade Federal da Integração LatinoAmericana (UNILA).

\section{A Pedagogia Translinguajeira e o Portfólio: práticas translíngues}

Após a descrição do contexto, dos personagens e da instrumentalização que envolverá a resposta para a pergunta deste trabalho que é: "considerando a sala de aula de Língua Portuguesa Adicional como um entre-lugar e terceira margem, bem como a visão dinâmica translíngue, transcultural e descolonial, quais são os discursos translíngues produzidos na sala de aula de PLA?” faz-se necessário focalizar o incentivo e o impulso para o surgimento das manifestações translíngues em sala de aula. Tal promoção translinguajeira, transcultural e descolonial poderá realizar-se por meio da Pedagogia Translíngue (CELIC \& SELTZER, 2012). García e Seltzer (2015) afirmam que as manifestações translíngues são como se fossem uma corrente perene de um rio que não para de fluir e que os trans-sujeitos precisam navegar nessa corrente contínua e fluida entre uma margem e outra, na terceira margem, a fim de, por meio de seus repertórios linguísticos vivos e dinâmicos, aprenderem e desenvolver maneiras de usarem o linguajamento, ampliando-o e desenterrando as vozes que estão abafadas e não podem ser ouvidas. Esse é o objetivo principal da Pedagogia Translíngue. Para García e Seltzer (2015), tal corrente contínua e fluida, às vezes pode ser vista por meio das manifestações discursivas, outras vezes, ela não pode ser vista, mas está sempre presente. Isto quer dizer que não é necessária a presença de duas ou mais línguas no discurso para que possamos identificar as translinguagens. Apesar de elas, em alguns momentos, estarem manifestadas por meio de um único traço linguístico como a Língua Portuguesa, elas advêm de um mesmo repertório linguístico, onde estão presentes todas as línguas faladas pelo transsujeito. Por exemplo, um aluno haitiano pode produzir um discurso em língua portuguesa, apesar de sua prosódia ser francófona ou alguma construção sintática que ele produziu em língua portuguesa ser mais frequente na língua francesa. Independentemente de ele estar produzindo um discurso em língua portuguesa na sala de aula ou fora dela, ele estará utilizando uma parte de todo o seu repertório linguístico, que inclui o criolo de língua francesa, a língua francesa e outras línguas que ele aprendeu. Por essa razão, a corrente translinguajeira pode ou não estar linguisticamente manifestada no discurso.

De acordo com Garcia e Seltzer (2016), a construção de um espaço translíngue reflete a paisagem linguística do contexto multilíngue e plurilíngue da sala de aula, como também diversas maneiras de se usar as línguas na sala de aula, na interação de uns com os outros. 
Ademais, um espaço de conscientização metalinguística pode ser criado, bem como um espaço de tolerância e respeito à diversidade linguística e cultural, que vai contra as hierarquias linguísticas e culturais. $\mathrm{O}$ envolvimento dos familiares também são considerados. O professor pode aproveitar os repertórios linguísticos existentes em sala de aula para agir como um co-aprendiz, reconhecendo e construindo oportunidades para colocar em interação as diferentes línguas presentes em sala de aula. Essa pedagogia contribui para que os aprendizes e o professor se apercebam da complexidade e do dinamismo do bilinguismo, trazendo à tona o bilinguismo dinâmico, no sentido de atrair os repertórios linguísticos dos alunos, com o objetivo de performá-los em diferentes contextos, sejam eles formais ou informais. Portanto, a Pedagogia Translíngue preconiza um trans-sujeito que muda as perspectivas da conversação, que ruma agora para a justiça social, desenterrando vozes minoritárias que até então estavam apagadas ou esquecidas. Para García e Seltzer (2015), a Pedagogia Translíngue faz com que as práticas translinguajeiras equalizem as distâncias entre as práticas linguísticas presentes no dia-a-dia e aquelas desejadas pelo contexto escolar e universitário, liberando e incluindo as vozes multilíngues dos falantes que foram repreendidas pela escola e reconhecendo o uso multilíngue e plurilíngue dos alunos e professor em sala de aula. A prática translíngue é muito mais do que um apoio para o aprendizado, sendo também uma maneira política diferente de olhar para as interações como expressivas, criativas, transformacionais e inclusivas, visando à justiça social.

A seguir, uma breve exposição sobre os Portfólios, a partir dos quais foram analisados os discursos translinguajeiros, em sala de aula de PLA.

\subsection{O Portfólio e as práticas translinguajeiras}

Como criar um ambiente escolar e de sala de aula que celebra as diferentes culturas e repertórios linguísticos e como sensibilizá-los da legitimidade dessas práticas? O Portfólio pode contemplar várias seções e pode permanecer com os alunos, lembrando-os sempre dos seus progressos em sala de aula. Ele pode ter três seções, de acordo com Celic e Seltzer (2012): (1) a seção biográfica; (2) a seção passaporte; e (3) a seção dossiê. Na seção biográfica (1), os alunos descrevem suas experiências nas diferentes línguas e culturas. Qualquer aluno pode criar sua própria seção biográfica, pois é um lugar onde eles podem observar seus objetivos de aprendizagem de línguas como também o que eles já conseguiram apreender e a usar. Também é um lugar para os alunos observarem seus entendimentos interculturais e transculturais. A seção passaporte (2) inclui tipos de listas e tabelas onde os 
aprendizes podem registrar o progresso dos seus aprendizados em diferentes línguas. A seção dossiê (3) é o espaço onde os alunos registram as atividades que eles fizeram em sala de aula, bem como suas conquistas linguísticas.

Os alunos foram orientados em sala de aula a escreverem um Portfólio como trabalho final para o curso de Língua Portuguesa Adicional de nível básico e para o curso de Língua Portuguesa Adicional de nível intermediário I e II, ambos ministrados na Universidade Federal da Integração Latino-Americana (UNILA), na cidade de Foz do Iguaçu no Paraná. Neste portfólio, os aprendizes deveriam escrever um texto para ser apresentado como trabalho final contendo introdução, desenvolvimento e conclusão. Na Introdução, eles deveriam se apresentar, dizendo de onde vieram, qual era o curso que eles faziam na universidade, as razões pelas quais eles escolheram a UNILA para estudarem e se já tiveram contato ou estudado a língua portuguesa. No desenvolvimento, eles deveriam escolher quatro tarefas distribuídas entre as várias unidades da coleção "Brasil Intercultural - Língua e cultura brasileira para estrangeiros", vistas durante o semestre, e tecer uma análise sobre elas, explicitando suas percepções de aprendizagem, como também as facilidades e dificuldades encontradas durante a feitura da tarefa. Na conclusão, além de avaliarem seu próprio aprendizado e dificuldades encontradas em sala de aula, eles deveriam avaliar a didática do professor que ministrou as disciplinas, o material utilizado nas disciplinas, bem como dar sugestões sobre o que poderia ser modificado nas aulas.

Algumas perguntas (GENESEE \& UPSHUR:1996) foram dadas como guias para produção do texto final como, por exemplo, na seção do Desenvolvimento, eles deveriam responder: por que você escolheu esta tarefa?; o que faz estas tarefas serem interessantes, em sua opinião?; qual foi a parte mais difícil desta tarefa?; o que você aprendeu ao fazer esta tarefa?; quais práticas você utilizou ao fazer esta tarefa (compreensão oral ou escuta, produção oral ou fala, compreensão escrita ou leitura e produção escrita)?; o que diferencia esta tarefa das outras que estão presentes neste portfólio?; qual é o ponto forte deste portfólio e por quê?; qual é o ponto fraco deste portfólio e por quê?; e quais recursos você utilizou para fazer este portfólio?

Os alunos foram orientados sobre o portfólio no início do semestre e durante a metade do semestre foi pedido para eles trazerem o que já haviam feito até aquele momento, pois eles precisavam compartilhar suas ideias com os colegas, respondendo às seguintes perguntas, conforme sugerem Genesee \& Upshur (1996): quais tarefas e materiais seu/sua colega incluiu no portfólio dele ou dela?; a maioria dos materiais foram tarefas desenvolvidas em sala de aula? Quais?; escreva sugestões de tarefas ou materiais que seu/sua colega poderia incluir no 
portfólio dele ou dela; pergunte ao seu/sua colega em qual tarefa ele mais aprendeu a língua portuguesa e por quê; pergunte ao seu colega em qual tarefa ele menos aprendeu a língua portuguesa e por quê; escreva comentários que você acha que ajudará seu/sua colega a melhorar o portfólio dele ou dela, mostrando o seu desenvolvimento durante o semestre.

A seguir, alguns exemplos das práticas translíngues que foram produzidas na terceira margem e no entre-lugar da sala de aula de PLA em contexto transfronteiriço, serão analisadas.

\section{Travessias: Análise das práticas translíngues:}

As práticas translíngues ${ }^{1314}$, presentes nos portfólios ${ }^{15}$ dos alunos, serão apresentadas e analisadas nesta seção.

O primeiro portfólio foi escrito por um aluno colombiano, que cursa Biotecnologia. No momento em que ele produziu este excerto, no primeiro semestre de 2016, estava cursando o nível Básico, no Ciclo Comum de Estudos da UNILA.

\section{Excerto 1.}

Nesta atividade eu poderia aprender em que parte de Brasil moro, que a primeira vez veio a este país, aprendi como está dividida Brasil em sus muitos estados, pequenos outros muito grandes, na ubicación de alguns de ellos (entre eles o estado de Minas Gerais de donde es nosso professor), que constantemente se enorgullece falar)... também aprendimos que o clima es muy diferente de um estado a outro já que Brasil es muy grande... que Brasil tem una parte de amazonas onde se encontram animais selvagens aun... Nesta unidade também aprendimos que Brasil não é só futebol y samba mas muchísimas cosas más, que la UNILA se encontra em Foz de Iguaçu, estado de Paraná y que este esta al sul de Brasil na fronteira com Paraguai e Argentina, separadas pelo Rio Paraná. (Carlos, estudante colombiano, nível Básico)

Note-se, nesse excerto, o surgimento de vozes bilíngues que se adaptam flexivelmente e criativamente aos abismos e cumes da comunicação. O estudante colombiano descreve suas impressões sobre a Unidade 0, denominada, "Conhecendo o Brasil", do livro Brasil Intercultural, utilizado em sala de aula, que versa sobre as imagens que os alunos têm do

\footnotetext{
${ }^{14}$ As transcrições mantiveram a escrita dos alunos exatamente como elas foram produzidas nos portfólios.

${ }^{15}$ Os nomes dos aprendizes foram trocados, a fim de preservar suas identidades.
} 
Brasil. O aluno utiliza palavras que ora pertencem aos traços linguísticos da Língua Portuguesa e ora pertencem aos traços linguísticos da Língua Espanhola, como por exemplo, sus, ubicación, enorgullece, es, muy, aprendimos, donde, y, muchísismas, cosas, más. É interessante notar que este aluno consegue comunicar seu entendimento sobre os Estados brasileiros, sobre onde está localizada a universidade onde ele estuda, sobre onde está a fronteira onde ele mora atualmente, por meio de um discurso translíngue. É esse linguajamento autopoiético (MATURANA \& VARELA, 1998) que permitirá a construção do contraponto transcultural (ORTÍZ, 2002), quando surge um entendimento novo, um dado contingente, pois, para que o colombiano se integre no Brasil, precisa entender o lugar onde está. Essa leitura de localização feita pelas lentes colombianas, pelo discurso translíngue (GARCÍA \& LEIVA, 2014), permite a criação de um espaço que não é mais colombiano, nem brasileiro, mas sim um espaço fluido transcultural, um entre-lugar, uma terceira margem, uma vez que a leitura do espaço brasileiro, feita pelo colombiano, já permite novas impressões sobre esse espaço.

O excerto a seguir é de uma aluna haitiana, nível Intermediário II, que cursa Ciências Econômicas - Economia, Integração e Desenvolvimento.

\section{Excerto 2}

Porquoi as-tu peur? (Por que estas com medo?)

Eu fiz uma comparação entre a utilisação de palavras (porquês) quanto em francês quanto em portugués para conseguir entender o uso de "porques",.

Nós temos:

Portugués

Porquê

Francés

Por que

Pourquoi

Porque

Pour quoi

Por quê

1) Pourquoi: é um advérbio interrogativo utilizado para pedir "qual razão" = "quelle raison", e com o artigo "le" = "o" (le pourquoi) é também um substantivo.

2) Pour quoi: em duas (2) palavras significa-se: "para que/ para que coisa? - pour quelle raison/par le fait que?" Pour-preposição e quoi-pronome relativo.

3) Com a minha grande surpresa existe 4 "porquês"tipo homófono em português. Com isso, percebi a grande diferença no campo linguística. Como eu aprendi na sala de aula com o professor que cada língua é uma língua. (Marie, estudante haitiana, nível intermediário II) 
A aluna falou do uso dos "porquês" porque esse tema foi trabalhado na Unidade 04 do livro didático "Brasil Intercultural: Língua e cultura brasileira para estrangeiros - Ciclo Avançado - Níveis 5 e 6". O livro é dividido em três seções: (1) Ponto de Partida, por meio da introdução de assuntos diversos relacionados ao cotidiano às culturas brasileiras; (2) Interação, onde são trabalhados, por meio de diferentes gêneros textuais, as compreensões oral e escrita (escuta e leitura, respectivamente) e as produções oral e escrita (fala e textos escritos, respectivamente); e a (3) Análise Linguística, que trabalha a ortografia, a fonética e a gramática. Nessa última seção, muitos aspectos linguísticos da língua portuguesa são trabalhados de forma contrastiva com os aspectos linguísticos da língua espanhola, uma vez que o livro foi produzido por professores brasileiros e argentinos de língua portuguesa adicional para ser utilizado pelo público argentino, bem como para o público hispanofalante em geral. Como a UNILA possui, em sua maioria, alunos cuja língua materna é a língua espanhola, essa coleção Brasil Intercultural pode ser adotada nas disciplinas de Língua Portuguesa Adicional do Ciclo Comum de Estudos da UNILA. Neste caso, a translinguagem refere-se aos traços da língua francesa e traços da língua portuguesa, utilizadas pela aluna para que pudesse entender o uso dos "porquês”, em língua portuguesa.

Todo esse excerto é metadiscursivo, pois a aluna utiliza a comparação dos aspectos linguísticos, neste caso o uso dos "porquês", da sua língua materna, o francês (pourquoi e por quoi), par apreender a língua portuguesa. Interessantemente, ela faz a pergunta "Por que estas com medo?" no início de sua exposição para acabar com o mistério dos "porquês" em língua portuguesa, pois, por meio da comparação entre as duas línguas, ela conseguiu entender, inclusive se surpreendeu quando disse "para minha grande surpresa existe 4 'porquês' em português", quando em francês existem apenas dois "porquês". As translinguagens são manifestadas aqui nos traços da sua língua materna, o francês, e nos traços da língua que está aprendendo, o português, a fim de apreender um aspecto linguístico da língua portuguesa. Tais traços utilizados nesse excerto fazem parte de um único e mesmo repertório linguístico dessa aluna haitiana.

O próximo excerto foi produzido por uma aluna chilena, do nível Intermediário I, que cursa Ciências Econômicas: Economia, Integração e Desenvolvimento e cursou a disciplina de Língua Portuguesa Adicional no segundo semestre de 2015.

\section{Excerto 3}


Minha critica possitiva para o professor é um excelente professor, tem muito conhecimento por sua língua como em outras (inglês, espanhol e francês), e é muito bom para um aula que tem culturas e línguas diferentes, como o guarani, o criollo haitiano, o quéchua e o aymara, por que assim eu e meus colegas (hispanofalantes e haitianos) entendemos muito melhor as coisas e o mismo conteúdo. (Mirela, estudante chilena, nível intermediário I).

O excerto a seguir foi produzido por uma estudante colombiana do nível básico, do curso de Arquitetura e Urbanismo, que fez a disciplina de Língua Portuguesa Adicional no primeiro semestre letivo de 2016.

\section{Excerto 4}

Eu escolhi esta atividade porque achei interessante me-lembrar das regras do espanhol que as vezes a gente esquece. Lembrando estas e fazendo os exercícios na aula, eu consegui compreender muito melhor. Lembre regras do espanhol e aprendi as de português. iQue ótimo! Também não há sonidos muito cerrados e abertos como em português, eu achei esquisito como são as silabas tônicas, tipo o acento circunflexo e a tilde de nasalidade que como já falé nas outras atividades não existem esses sonidos no alfabeto do espanhol. A pronunciação destas eu achei muito difícil, e ainda é assim, mas com estas regras e as atividades nas aulas de pronuncia eu estou melhorando e tentando avançar no processo. (Alejandra, estudante colombiana, nível básico)

Nesses excertos, os alunos consideram que, além da integração, houve a utilização de várias outras línguas na aula de língua portuguesa, como a língua inglesa, a língua francesa, o crioulo de base francesa, a língua quéchua, a língua guarani e a língua aymara, embora não tenham ocorrido nos portfólios. No excerto da estudante chilena Mirela, ela ressalta o fato positivo de o professor ter domínio de outros idiomas, como o inglês, o francês e o espanhol, além da importância do domínio da sua língua materna que é o português. Tal excerto dialoga com o último excerto da aluna colombiana Alejandra, do nível básico. Quando ela está estudando a acentuação gráfica, em língua portuguesa, além do estranhamento inicial pelo fato de as línguas portuguesa e espanhola terem um sistema de acentuação diferente, salvo algumas regras mais simples, ela também se lembra da acentuação em sua língua materna, o espanhol, quando está estudando a acentuação, em português. Quando fala sobre as diferenças 
fonéticas entre o português e o espanhol, ela inclusive utiliza palavras do espanhol, como sonidos e cerrados, la tilde, caracterizando a translinguagem (GARCIA \& LEIVA, 2014). Tal fato a ajuda a compreender as diferenças e semelhanças, tanto na acentuação da língua portuguesa, como na da língua espanhola. O uso de outras línguas na sala de aula de PLA, sem que isto seja visto como inadequado, corrobora o pensamento liminar e descolonial (MIGNOLO, 2000), pois a aula não é dada predominantemente nas duas línguas oficiais da UNILA, quais sejam, o Português e o Espanhol, o que faz com que outras vozes, em outras línguas surjam nas práticas translinguajeiras e ajudem na criação desse espaço anticolonizador e descolonial, em que não há uma hierarquização entre as diferentes práticas de linguagem. O uso e a valorização dessas línguas enaltecem os saberes considerados subalternos em detrimento do pensamento colonizador dominante do sistema colonial/moderno, fazendo com que os estudantes e o professor possam pensar entre essas línguas, criando uma forma de viver e de pensar um mundo diferente do status quo vigente, por meio das lentes da diferença colonial. Criam, então, um bilinguajamento político de luta, de resistência e também de libertação dessas vozes que são, muitas vezes, apagadas pelo sistema dominante. Nota-se aqui que a terceira margem para as translinguagens emerge em sala de aula de PLA a partir do momento que o professor permite o surgimento de outras vozes em sala de aula para que elas possam ser negociadas, visando o aprendizado de língua portuguesa. Esse espaço refletirá a flexibilidade, o dinamismo, a capacidade crítica e a adaptabilidade que os alunos e o professor devem ter para a construção da autopoiesis (MATURANA \& VARELA, 1998) contínua, interminável e processual que caracteriza o linguajamento translíngue.

O último excerto pertence ao estudante Ramón, de El Salvador, do curso de Engenharia de Energias Renováveis, nível Intermediário II.

\section{Excerto 5}

No Brasil tem muita música boa e que quase nadie conoce mucho. Eu percebi que a música que os hispanoablantes escutam não escutam a maioria dos brasileiros, aconteceu com um colega que a gente estava escutando música muita antiga, música legal para nós, nós falamos "música del recuerdo" e ele ficou sorpreendido e não gostou da música. (Ramón, estudante salvadorenho, nível Intermediário II) 
O aluno salvadorenho utilizou seu repertório linguístico para externar sua opinião sobre uma manifestação artística muito comum no Brasil: a música. Por meio de suas práticas translíngues, ele ressaltou que, em seu país e nos países dos colegas hispanoablantes, escutar música antiga ou musica del recuerdo é uma prática comum entre os jovens. Esse fato deixou o colega brasileiro sorpreendido, pois, no contexto onde estavam, não era uma prática comum que os jovens brasileiros escutassem músicas antigas. Escutar música del recuerdo, para ele, é uma maneira de resgatar a voz cultural de seu país e é, ao mesmo tempo, uma maneira de o aluno estar mais próximo da sua família e de seus amigos. Para esse aluno salvadorenho, os brasileiros deveriam conhecer mais a música brasileira. Em sua opinião, infelizmente, quase nadie conoce mucho (ninguém conhece muito), o que impede que, tanto os mais velhos como os mais jovens, possam usufruir dessa manifestação cultural brasileira. $\mathrm{O}$ contato desse aluno salvadorenho com a cultura brasileira fez emergir um novo espaço transcultural (ORTÍZ, 2002), um espaço contrapontístico onde, por meio de sua influência, ele poderá fazer com que seu colega brasileiro escute e valorize a música antiga brasileira e quiçá, a música del recuerdo que tanto lhe apraz.

\section{Considerações Finais: travessias futuras}

Voltemos à pergunta inicial que norteia este trabalho: "considerando a sala de aula de Língua Portuguesa Adicional como um entre-lugar e terceira margem, bem como a visão dinâmica do falante translíngue, quais são as práticas translinguajeiras produzidas na sala de aula de PLA?" Essa pergunta é respondida por meio das análises tergiversadas acima.

A Pedagogia Translíngue coloca luz sobre os verdadeiros protagonistas do ensinoaprendizagem das línguas: os trans-sujeitos, sejam eles estudantes ou professores. Portanto, é a perspectiva do falante que é considerada, e não a perspectiva das línguas como construtos sociais, políticos e culturais. É o repertório linguístico dinâmico e vivo construído cognitivamente, culturalmente e socialmente, que estará em foco. E mais importante: para García e Seltzer (2015), a Pedagogia Translíngue faz com que as práticas translinguajeiras equalizem as distâncias entre as práticas linguísticas presentes no dia-a-dia e aquelas desejadas pelo contexto escolar e universitário, liberando e incluindo as vozes multilíngues dos falantes, as quais geralmente são censuradas no contexto escolar. Dessa forma, houve espaço para o uso multilíngue dos alunos e professor em sala de aula, compreendendo-se que a prática translíngue é muito mais do que um apoio para o aprendizado, sendo também uma 
maneira diferente de olhar para as interações como expressivas, transformacionais e inclusivas, visando à justiça social.

Por meio das diversas translinguagens presentes e produzidas por alunos de origens diversas, este artigo apresentou como a flexibilidade dessas translinguagens pode contribuir para que os alunos tomem a sua voz, transformando-os para lidarem não somente com o ambiente acadêmico onde se encontram, com todos os seus prós e contras, mas também os preparando para os enfrentamentos locais, globais, políticos, sociais e culturais que podem vir a ocorrer em um mundo que, infelizmente, revela-se cada vez mais adverso, desrespeitoso, preconceituoso e rude, principalmente para com aqueles que sempre tiveram suas vozes, línguas e direitos apagados e desvalorizados pelo status quo vigente. As translinguagens produzidas em sala de aula e expostas neste artigo tornam evidente que não se pode separar as práticas de linguagem ou linguajamento da maneira como percebemos o mundo, nossa autopoiesis (MATURANA \& VARELA, 1998). Torna evidente também a necessidade de assumir um entre-lugar, uma terceira margem legítima, caracterizada pela adaptabilidade às crateras e cumes da conversação, caracterizada pelo contraponto, pelo espaço e realidade novos e contínuos que vão surgir da interação entre diferentes culturas - a transculturação (ORTÍZ, 2002) - pela flexibilidade e pela resistência às assimetrias de poder (MIGNOLO, 2000) instaladas pelas práticas linguísticas padronizadas da escola ou da universidade.

Destarte, nasce a urgência em discutirmos, cada vez mais, os papéis das políticas linguísticas, de novas epistemologias nas culturas acadêmicas, de práticas pedagógicas e de sistemas educacionais que não mais consideram as línguas como sistemas obedientes às estruturas dominadoras modernas/coloniais autônomas, fechadas e segmentadas. Não obstante, devemos discutir a necessidade da inclusão das minorias que foram apagadas ou silenciadas pelos discursos dominantes e colonizadores nos espaços trans-nacionais e transfronteiriços das salas de aula, estejam elas localizadas na fluidez e porosidade das fronteiras ou nos labirintos e veredas líquidas dos sertões. As fronteiras também podem ser encontradas nos sertões. Não precisamos estar em uma fronteira geográfica para discutirmos todas essas questões. A valorização dos dicursos translíngues presentes em sala de aula pode sensibilizar os estudantes e os professores a habitarem as fronteiras, sejam elas físicas ou emocionais. Podem sensibilizá-los a sentir, a pensar, a performar e a visibilizar a fronteira, não como um lugar que separa e fragmenta, mas sim como um espaço que une, que integra, que inclui e que transforma para a justiça social, estejam esses trans-sujeitos onde estiverem.

\section{Referências Bibliográficas}


BAKHTIN, M. Dialogic imagination: four essays. Austin: University of Texas Press, 1981.

BHABA, H.K. O local da cultura. Belo Horizonte: Editora UFMG, 2004.

BLACKLEDGE, A.; CREESE, A. Multilingualism. London: Continuum, 2010.

BLOMMAERT, J. The sociolinguistics of globalization. Cambridge: Cambridge University Press, 2010.

CANAGARAJAH, A. S. Codemeshing in academic writing: Identifying teachable strategies of translanguaging. The Modern Language Journal 95 (iii), 2011.

CELIC, C.; SELTZER, K. Translanguaging: A CUNY-NYSIEB Guide for Educators. New York: CUNY-NYSIEB, 2012.

CORONIL, F. Transculturation and the politics of theory: Countering the center: Cuban Counterpoint: Introduction. In: OR 'TZ, F. Cuban Counterpoint: Tobacco and Sugar. Durham: Duke University Press, 1995.

GARCÍA, O. Bilingual education in the $21^{\text {st }}$ Century: A global perspective. Malden: WileyBlackwell, 2009.

GARCÍA, O. From language garden to sustainable languaging: Bilingual education in a global world. Perspective. A publication of the National Association for Bilingual Education, 2011.

GARCÍA, O.; SYLVAN, C. Pedagogies and practices in multilingual classrooms: Singularities and Pluralities. Modern Language Journal 95 (iii), 2011.

GARCÍA, O.; LEIVA, C. Theorizing and Enacting Translanguaging for Social Justice. In: BLACKLEDGE, A.; CREESE, A. Heteroglossia as Practice and Pedagogy. Heidelberg, New York, London: Springer, 2014.

GARCÍA, O.; SELTZER, K. The Translanguaging Current in Language Education. Symposium. Stockholm University, 2015.

GENESEE, F.; UPSHUR, J.A. Classroom-based evaluation in Second Language Education. Cambridge: Cambridge University Press, 1996.

HELLER, M. Bilingualism as ideology and practice. In: Bilingualism: A social approach. Basingstoke: Macmillan, 2007.

HORNBERGER, N.; LINK, H. Translanguaging and transnational literacies in multilingual classrooms: A bilingual lens. International Journal of Bilingual Education and Bilingualism, 2012.

LEWIS, G.; JONES, B.; BAKER, C. Translanguaging: Developing its conceptualization and contextualization. In: Educational Research and Evaluation: An International Journal on Theory and Practice, DOI:10.1080/13803611.2012.718490, 2012.

MATURANA, H.; VARELA, F. The Tree of knowledge. The biological roots of human understanding. Boston and London: Shambhala, 1998.

MENDES, E. (Coord.). Brasil Intercultural: Língua e cultura brasileira para estrangeiros. Ciudad Autónoma de Buenos Aires: Casa do Brasil, 2014.

MIGNOLO, W. D. Histórias Locais / Projetos Globais: Colonialidade, Saberes Subalternos e Pensamento Liminar. Belo Horizonte: Editora UFMG, 2000. 
MINISTÉRIO DA EDUCAÇÃO; UNIVERSIDADE FEDERAL DA INTEGRAÇÃO LATINO-AMERICANA. Estatuto da UNILA. 2012.

ORTÍZ, F. Contrapunteo cubano del tabaco y el azúcar. Madrid: Cátedra, 2002

OTHEGUY, R.; GARCÍA, O.; REID, W. Clarifying translanguaging and deconstructing named languages: A perspective from linguistics. New York: De Gruyter Mouton, 2015.

PENNYCOOK, A. Language as Local Practice. London: Routledge, 2010.

PEREIRA CARNEIRO, C. Fronteiras irmãs: transfronteirizações na Bacia do Prata. Porto Alegre: Editora Ideograf, 2016.

ROSA, J. G. Grande sertão: Veredas. Rio de Janeiro: Nova Fronteira, 2015.

ROSA, J. G. Primeiras estórias. Rio de Janeiro: Nova Fronteira, 2015.

SCHLATTER, M.; GARCEZ, P. Referenciais Curriculares para o Ensino de Língua Espanhola e de Língua Inglesa. Rio Grande do Sul: Secretaria de Educação do Estado, 2009.

Sítio oficial da Universidade Federal da Integração Latino-Americana (UNILA). Disponível em: http://unila.edu.br. Acesso em: 04 de abril de 2017.

WILlIAMS, C. Arfamiad o Ddulliau Dygsu ac Addysgu yng Nghyd-destum Addysg Uwebradd Ddwylithog. Unpublished PhD thesis. Bangor: University of Wales, 1994. 